\title{
User preferences and usability of iVitality: optimizing an innovative online research platform for home-based health monitoring
}

This article was published in the following Dove Press journal:

Patient Preference and Adherence

30 June 2015

Number of times this article has been viewed

\author{
Mara van Osch' \\ AJM Rövekamp² \\ Stephanie N Bergman- \\ Agteres' \\ Liselotte W Wijsman ${ }^{3,4}$ \\ Sharon J Ooms ${ }^{5}$ \\ Simon P Mooijaart ${ }^{3,4,6}$ \\ Joan Vermeulen ${ }^{7}$
}

'Netherlands Institute for Health Services Research, Utrecht, ${ }^{2}$ Netherlands Organization for Applied Scientific Research, ${ }^{3}$ Department of Gerontology and Geriatrics, Leiden University Medical Centre, ${ }^{4}$ Netherlands Consortium for Healthy Ageing, Leiden, ${ }^{5}$ Department of Geriatric Medicine, Radboud Alzheimer Centre, Radboud University Nijmegen Medical Centre, Nijmegen, ${ }^{6}$ Institute for Evidence-Based Medicine in Old Age, Leiden, ${ }^{7}$ Research School, CAPHRI, Maastricht University, Maastricht, the Netherlands
Correspondence: Mara van Osch Netherlands Institute for Health Services Research, PO Box I568, 3500 BN

Utrecht, the Netherlands

$\mathrm{Tel}+3$ I 302729632

Fax +3। 302729729

Emailm.vanosch@nivel.nl
Background: The iVitality online research platform has been developed to gain insight into the relationship between early risk factors (ie, poorly controlled hypertension, physical or mental inactivity) and onset and possibly prevention of dementia. iVitality consists of a website, a smartphone application, and sensors that can monitor these indicators at home. Before iVitality can be implemented, it should fit the needs and preferences of users, ie, offspring of patients with dementia. This study aimed to explore users' motivation to participate in home-based health monitoring research, to formulate requirements based on users' preferences to optimize iVitality, and to test usability of the smartphone application of iVitality.

Methods: We recruited 13 participants (aged 42-64 years, 85\% female), who were offspring of patients with dementia. A user-centered methodology consisting of four iterative phases was used. Three semistructured interviews provided insight into motivation and acceptance of using iVitality (phase 1). A focus group with six participants elaborated on expectations and preferences regarding iVitality (phase 2). Findings from phase 1 and 2 were triangulated by two semistructured interviews (phase 3). Four participants assessed the usability of the smartphone application (phase 4) using a think aloud procedure and a questionnaire measuring ease and efficiency of use (scale 1-7; higher scores indicated better usability).

Results: All participants were highly motivated to contribute to dementia research. However, the frequency of home-based health monitoring should not be too high. Participants preferred to receive feedback about their measurements and information regarding the relationship between these measurements and dementia. Despite minor technical errors, iVitality was considered easy and efficient to use (mean score 5.50, standard deviation 1.71).

Conclusion: Offspring of patients with dementia are motivated to contribute to home-based monitoring research by using iVitality and are able to use the smartphone application. The formulated requirements will be embedded to optimize iVitality.

Keywords: e-health, m-health, technology, patient preferences, dementia, self-monitoring, usability

\section{Introduction}

Worldwide, approximately 33.9 million individuals suffer from dementia leading to progressive deterioration in cognitive ability and capacity for independent living. ${ }^{1,2}$ The number of individuals aged $\geq 60$ years with dementia worldwide is projected to double every 20 years, with an estimated increase to 115.4 million in $2050 .^{3}$ Although the last few decades have shown an increase in our understanding of the etiology of dementia, this has not yet been successfully translated into effective new treatments. To date, there are no intervention programs for prevention of dementia. 
Accumulating evidence shows that several risk factors are associated with an increased risk of dementia, including poorly controlled mid-life hypertension, obesity, and physical or mental inactivity. ${ }^{1,2,4}$ Preventive methods, such as control of mid-life hypertension and physical exercise, might be effective strategies to reduce the risk for dementia. ${ }^{1,5,6} \mathrm{How}-$ ever, according to a Cochrane review by Angevaren et al larger studies are still required to confirm these findings and to understand why such methods can improve cognitive functioning. ${ }^{5}$ Studies of the effect of preventive strategies are hampered by the fact that treatment or interventions should start before the onset of dementia, and should be continued for a longer time period. This makes these studies extremely large and expensive. The increasing uptake of innovative technologies by older persons, such as smartphones, (tablet) computers, and the Internet, enables large-scale, home-based data collection by telemonitoring. The collected data can provide a valuable insight into the effects of health-related and lifestyle-related risk factors on cognitive decline. Therefore, the use of technology can improve the efficiency of study designs in the field of dementia.

iVitality is an online research platform that consists of a website, a smartphone-based application, and sensors that are connected with or already integrated into the smartphone to monitor early risk factors associated with dementia, ie, blood pressure, physical activity, cognition, and lifestyle at home. The smartphone application collects data from the sensors and provides feedback to the user by graphically showing data of their measurements. We intend to use iVitality in a large-scale trial (PReservation Of Brain function in the Elderly, PROBE) to provide a better understanding of the relationship between these indicators and the onset and possibly prevention of dementia. The study population consists of offspring of patients with dementia because they have, due to their heredity, an increased risk of both hypertension and dementia. ${ }^{7,8}$ Additionally, they might be motivated to participate in research using homebased monitoring technology, given that they have been confronted with the suffering that dementia has caused to their parents and themselves.

Before iVitality can be implemented in large-scale studies, it should fit the needs and preferences of end-users. To ensure technical functioning and feasibility of the online platform, it is of importance to involve users in an early stage of the development process. Therefore, the objectives of this study were: to determine whether offspring of patients with dementia are motivated to participate in homebased monitoring research using iVitality; to formulate requirements based on expectations and preferences of offspring of patients with dementia to optimize iVitality; and to test the technical functioning and usability of the smartphone-based application of the online platform. The findings of this study will be used to optimize the iVitality platform. Feasibility and acceptance of the platform will be evaluated during a 6-month proof-of-principle (POP) study among 150 persons who are all offspring of patients with dementia.

\section{Materials and methods Overview of study design}

We used an iterative approach consisting of four phases (Figure 1) to determine users' motivation to use iVitality (phases 1 and 2), formulate requirements to optimize iVitality (phases 2 and 3), and test the usability of the smartphone application as part of the online platform (phase 4). This approach was chosen because multiple iterative phases continuously elicit, test, and evaluate users' expectations and preferences. ${ }^{9}$ In this way, triangulation will take place; multiple methods are used to collect and interpret data to ensure an accurate representation of these data. The goals and rationale for applying qualitative methods during the various phases are described in more detail below. In this study, a first prototype of the smartphone application was used in which blood pressure could be monitored using a wireless blood pressure monitoring device that forward measurements to the smartphone application via Bluetooth. Besides blood pressure monitoring, the smartphone application contained the following functionalities: graphical feedback about blood pressure values, cognition tests (measuring reaction time), physical activity monitoring (using a sensor built-in the smartphone), and lifestyle monitoring (by providing short questions about lifestyle patterns). The study took place between October 2012 and April 2013.

\section{Study participants}

Study participants were offspring of patients with dementia who were involved in all phases throughout the study. The main inclusion criterion was having at least one parent diagnosed with dementia. In addition, we chose to select middleaged (aged 40-65 years) offspring of dementia patients because of their increased risk for hypertension and dementia due to their family history. ${ }^{7,10}$ Because of their first-hand experience with the burden of the disease, we hypothesized that they would be motivated to engage in a longitudinal monitoring study to support preventive strategies for dementia. Participants were recruited through an advertisement in 


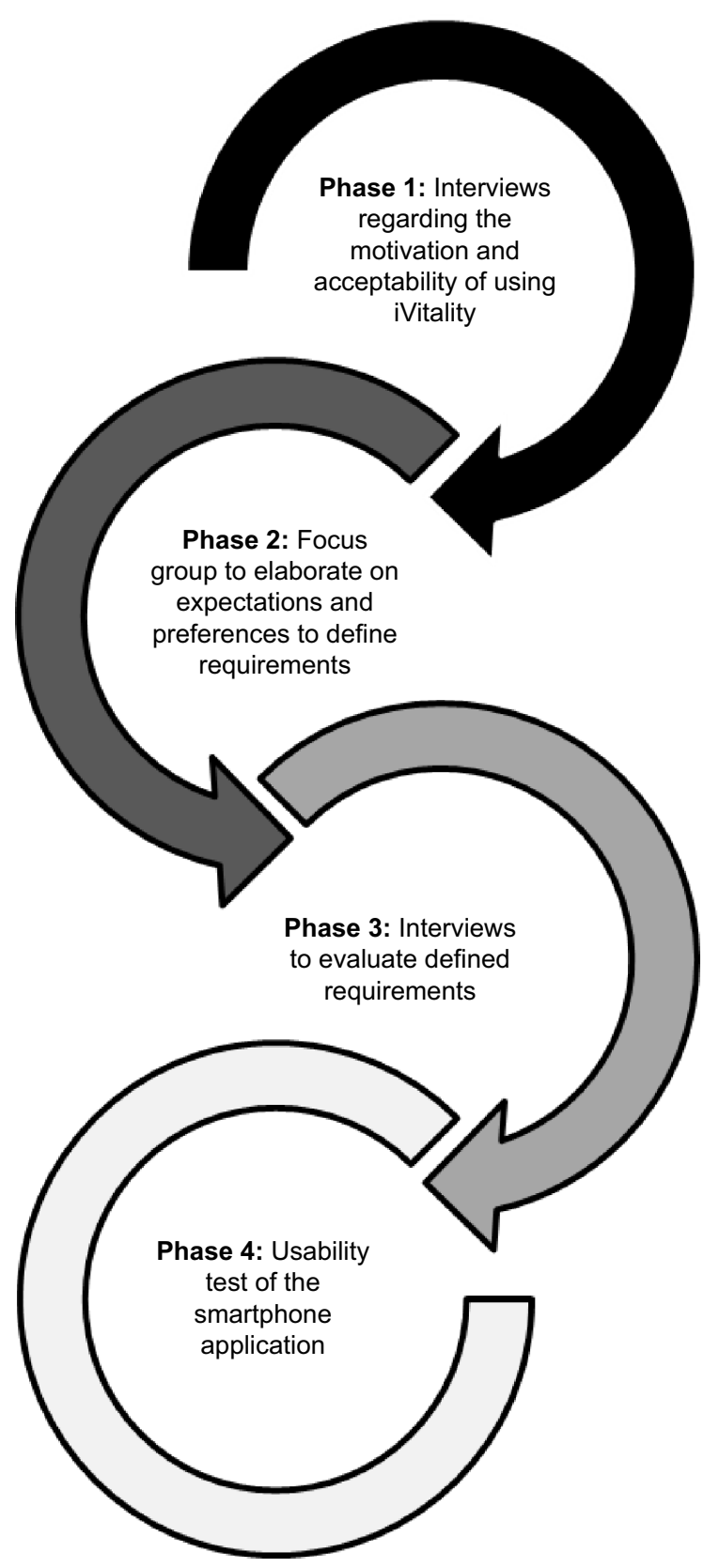

Figure I Schematic presentation of the iterative phases.

an online newsletter on the website of the Dutch Alzheimer Foundation. Interested participants received an information letter and an informed consent form specifying the details of the study phase for which they were invited for. For each phase, we aimed to recruit different participants. By including different participants in the different phases, we aimed to gain a broad perspective on the motivation and preferences of potential end-users of iVitality. In a large-scale POP panel study, expectations, acceptance, and experiences of iVitality will be tested among 150 patients with dementia over a period of 6 months.

\section{Procedures}

Phase I: motivation and acceptance of using iVitality Phase 1 consisted of three semistructured individual interviews aimed at gaining insight into the motivation and acceptance of using the iVitality research platform as a health monitor and if the subjects would consider using iVitality as a self-management tool and feedback aid in daily life. A semistructured setup was used to avoid the influence of preconceived notions and to allow participants to express themselves in their own terms. ${ }^{11}$ Participants were asked about the impact of dementia and health status of their parent(s), their own health status and lifestyle, their experiences with smartphone and Internet use, and their motivation, expectations, and preferences about selfmonitoring of health. The interviews lasted about 1 hour and generated questions and propositions for the focus group in phase 2 .

\section{Phase 2: elaborating on expectations and preferences to define requirements}

To formulate requirements and to elaborate further on expectations and preferences, a focus group was conducted. Before the focus group, six participants received a five-item questionnaire by postal mail about the dementia status of their parent(s), their own health status, and their attitude toward self-monitoring their health. This questionnaire aimed to sensitize participants and to prepare them for the focus group. This way, participants were encouraged to reflect freely on their experiences and feelings in their own context. The combination of these methods (in this case, completing a questionnaire and participating in a focus group) result from the context mapping framework. ${ }^{12}$ Context mapping is a frequently used method in the explorative phase of a design process, aimed at uncovering insights around the context and motivations of the people involved. In addition, it was expected that this method stimulated the quality and quantity of their contributions during the various sessions. ${ }^{13}$ The questionnaire was handed over to the researcher before the start of the session.

The focus group was semistructured to avoid the influence of preconceived notions and to encourage participants to express themselves. ${ }^{11}$ The setup of the session was structured according to the technology acceptance model and its extensions. ${ }^{14}$ This model can explain the user's perception of usefulness, ease of use, and intention to use the technology, thereby considering social and cognitive influential processes (eg, role of social influences and relevance of the system according to one's goals). During the first part of the 
session, the facilitator asked about the dementia status of their parent(s), their own health status, and their attitude about self-monitoring health to elaborate on the aforementioned motivations and preferences. During the second part of the session, the iVitality smartphone application was introduced to the participants through an illustrative video. Hereafter, participants could use the application themselves. The facilitator encouraged them to share their opinions and experiences, and to react to other's contribution(s). The session lasted approximately 2 hours. The participants not only provided input regarding the content, form, and layout of the (devices of the) iVitality platform itself, but also provided input on their preferences regarding use of these devices for homebased self-monitoring when participating in a longitudinal study (eg, frequency of use and time of use). Based on the interview in phase 1 and the conclusions of the focus group, requirements were formulated to optimize iVitality and the POP study protocol.

\section{Phase 3: evaluation of defined requirements}

Two participants first received the same five-item questionnaire (as described in phase 2) and participated in a semistructured individual interview. The aim of the interviews was to triangulate the previously defined requirements (eg, health monitoring for a 6-month period at set time intervals). The same iVitality smartphone application (version 1) as in phase 1 was demonstrated to the participants with the remark that for the next version (version 2) the functions and design would be different.

\section{Phase 4: usability of the smartphone application}

Individual usability tests of the smartphone application were conducted with four participants. The usability test consisted of two parts. First, participants performed seven tasks, in which they used the main functionalities of the iVitality smartphone application installed on an Android smartphone. Participants were asked to think aloud while performing the tasks. A researcher observed and recorded the reactions of the participants. Second, participants completed two questionnaires measuring usability and user's motivation, ie, the Post-Study System Usability Questionnaire (PSSUQ) ${ }^{15}$ and the Treatment Self-Regulation Questionnaire (TRSQ). ${ }^{16}$ The PSSUQ consisted of 24 items which can be scored in three domains: system's ease of use and efficiency in performing tasks, information quality, and interface quality. The PSSUQ was scored on a 7-point Likert scale ranging from 1 (strongly disagree) to 7 (strongly agree). Higher scores indicated higher usability. The TRSQ consists of twelve items assessing motivation for using the iVitality smartphone application on the domains of autonomous regulation (eg, "I find this important") and controlled regulation (eg, "I want others to approve of me"). Autonomous regulation refers to more intrinsic forms of motivation, whereas controlled regulation refers to extrinsic forms of motivation. ${ }^{16}$ The TSRQ was scored on a 7-point Likert scale ranging from 1 (strongly disagree) to 7 (strongly agree). Higher scores refer to higher agreement.

Based on phases 3 and 4, additional recommendations were made according to the requirements for optimization of the iVitality smartphone application, for both the Android and IOS system, and the POP study protocol.

\section{Data analyses}

Audio-recorded interviews, the focus group, and observations and comments were transcribed verbatim. These data were coded using a template analysis, or so-called code book analysis. A list of codes was developed by the researcher, representing identified themes in the data set. ${ }^{17}$ These codes were predefined with categories taken from the technology acceptance model (ie, perceived usefulness and perceived ease of use), ${ }^{14}$ while other codes were defined based on empirical data. MAXQDA software was used for the coding procedure. ${ }^{18}$

Data from the usability evaluation were analyzed by coding the most relevant reactions based on the think aloud approach or by observations on how participants used the smartphone application. For the PSSUQ ${ }^{15}$ and TSRQ, ${ }^{16}$ average scores were calculated per domain.

\section{Results}

\section{Participants}

All 13 participants (aged 43-66 years, 85\% female) were offspring of patients with dementia. Table 1 presents their characteristics. Most participants already used smartphones and all had Internet experience. Two of the 13 participants did not use a smartphone but were willing to buy one for iVitality research purposes.

\section{Phase I: motivation and acceptance of using iVitality}

Results of the interviews ( $n=3)$ revealed that the participants were highly motivated to contribute to research aimed at increasing knowledge about dementia. Dementia in their parent(s) caused deep personal suffering in participants' lives and the lives of their parent(s). Participants expressed that they felt that their risk of developing dementia was increased because of their family history. Some were afraid of developing the disease themselves and were motivated 
Table I Participant characteristics

\begin{tabular}{|c|c|c|c|c|}
\hline \multirow[t]{2}{*}{ Variable } & \multirow{2}{*}{$\begin{array}{l}\text { Phase I } \\
\text { Interview I } \\
(n=3)\end{array}$} & \multirow{2}{*}{$\begin{array}{l}\text { Phase } 2 \\
\text { Focus group } \\
(\mathrm{n}=6)\end{array}$} & \multirow{2}{*}{$\begin{array}{l}\text { Phase } 3 \\
\text { Interview } 2 \\
(n=2)\end{array}$} & \multirow{2}{*}{$\begin{array}{l}\text { Phase } 4 \\
\text { Usability evaluation } \\
(n=4)\end{array}$} \\
\hline & & & & \\
\hline Sex (male/female) & $\mathrm{I} / 2$ & $1 / 5$ & $0 / 2$ & $1 / 3$ \\
\hline Age, years (male/female) & $53 / 55,62$ & $53 / 42,55,58,63,64$ & 50,51 & $53 / 43,61,62$ \\
\hline \multicolumn{5}{|l|}{ Highest education } \\
\hline Middle & I of 3 & 4 of 6 & - & 3 of 4 \\
\hline High & 2 of 3 & 2 of 6 & 2 of 2 & I of 4 \\
\hline $\begin{array}{l}\text { Experience in using a } \\
\text { smartphone }(n)\end{array}$ & 2 of 3 & 3 of 6 & 2 of 2 & 2 of 4 \\
\hline Experience in using & 3 of 3 & 6 of 6 & 2 of 2 & 4 of 4 \\
\hline
\end{tabular}

Notes: Two participants of the first interview also participated in the focus group, making a total of 13 participants. Highest education can refer to: middle education (secondary school + vocational education) or high education (higher vocational education or university).

to take preventive measures to delay onset of dementia. They started seeking information on the Dutch Alzheimer Foundation Internet pages and through magazines about dementia, recent developments, and information about preventing or delaying dementia. The relationship between hypertension and development of dementia was unknown to all participants.

Participants indicated that they were willing to perform all tasks required for the study to collect data. They were aware that the study will not directly benefit them in any way. Participants preferred receiving feedback on their measured values. Timing of measurements and the time commitment were rated as important factors for successful monitoring.

\section{Phase 2: elaborating expectations and preferences to define requirements}

The focus group $(n=6)$ confirmed the results obtained from phase 1. Due to their first-hand experience with the disease of their parent(s) and the lack of successful prevention programs, participants were highly motivated to contribute to dementia research. Participants gave high priority to dementia-related studies, without expecting anything in return (Quote K3 [female, 56 years]: “Actually, you make such a small contribution in a large study in which other people are more likely to benefit than me"). They primarily indicated to be willing to perform home-based health measurements to contribute to research, although they also considered it of importance to monitor their own health. Monitoring one's health in relation to dementia was not foreseen.

The session further elaborated on the mentioned factors regarding self-monitoring and also on how the relationship between high blood pressure and the risk for developing dementia could be explained better. When monitoring blood pressure at home, the current literature and guidelines recommend that blood pressure should be monitored twice per day (morning and evening) by performing two consecutive measurements for 4 days a week. Participants considered it impractical to follow these guidelines for a lengthy period of time (eg, 6 months) due to work or exceptional circumstances such as vacations. In addition, not all participants preferred receiving daily questions about their lifestyle. This would remind them and keep them too preoccupied with the idea of being at risk for dementia. Further, participants preferred some adjustments in the graphical representation of their measured data. A graphical output of the first version of the smartphone application is shown in Figure 2A. Some participants mentioned preferring a reference line in the graph reflecting blood pressure values indicating the accepted range of blood pressure according to their age group. Therefore, during phase 4 , the usefulness of a new graphical design was tested, representing the measured blood pressure values along with a reference line as shown in Figure 2B. In addition, participants indicated that they would like to receive information about blood pressure and lifestyle regarding dementia alongside their data. This could increase their awareness of the relationship between health, lifestyle, and dementia.

In summary, although participants stated to have the intention to use the iVitality smartphone application (as both phases 1 and 2 revealed), its perceived usefulness and ease of use depends on the measurement protocol (ie, time interval, type of questions) and its visual abilities/features.

\section{Phase 3: evaluation of defined requirements}

Results from the interviews ( $\mathrm{n}=2$ ) confirmed that participants were highly motivated to participate in a home-based health monitoring study using iVitality. (Quote K7 (female, 51 years): "I'm terrified that I will also develop Alzheimer's disease. And because of that I'm highly interested in the latest developments 


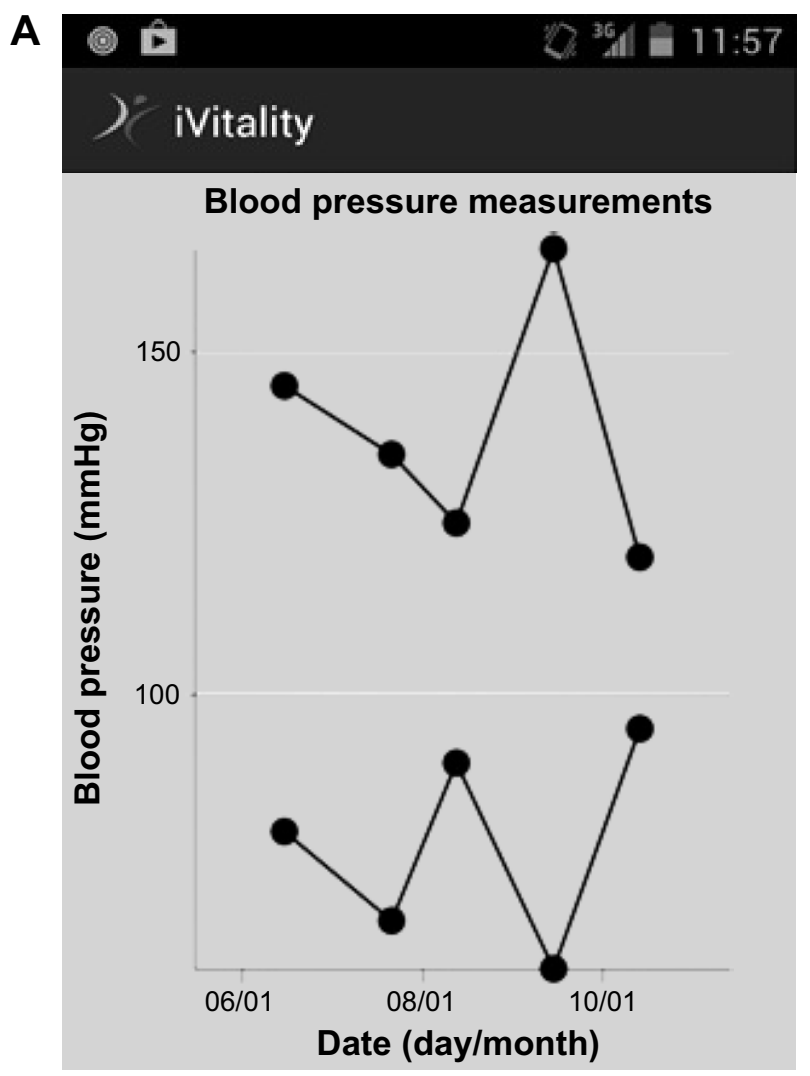

Figure 2 (A) Blood pressure measurements in original iVitality smartphone application.

in research.”) They perceived the smartphone application as an important, user-friendly, and useful research tool. Both participants were willing to perform all features in the iVitality smartphone application, measuring blood pressure, physical activity, cognition, and answering lifestyle questions when this was required for the study. Neither participant foresaw problems in using the iVitality smartphone application. One participant indicated that they were willing to use the iVitality application mainly for the aim of the research. The other participant indicated that, besides supporting research, she would also be interested in the measurements because they can help her to monitor her own health and lifestyle.

\section{Phase 4: usability of the smartphone application}

Table 2 shows the results of the usability tasks. Participants experienced problems related to, for example, unclear notifications, menu navigations, and unclear graphical presentations. Interpretation of the proposed graphical presentation presented in Figure 2B (ie, reference lines stating mild or severe hypertension, displayed by the gray and black line, respectively) without additional explanation about what the graphs represented was difficult for participants.

\section{B}

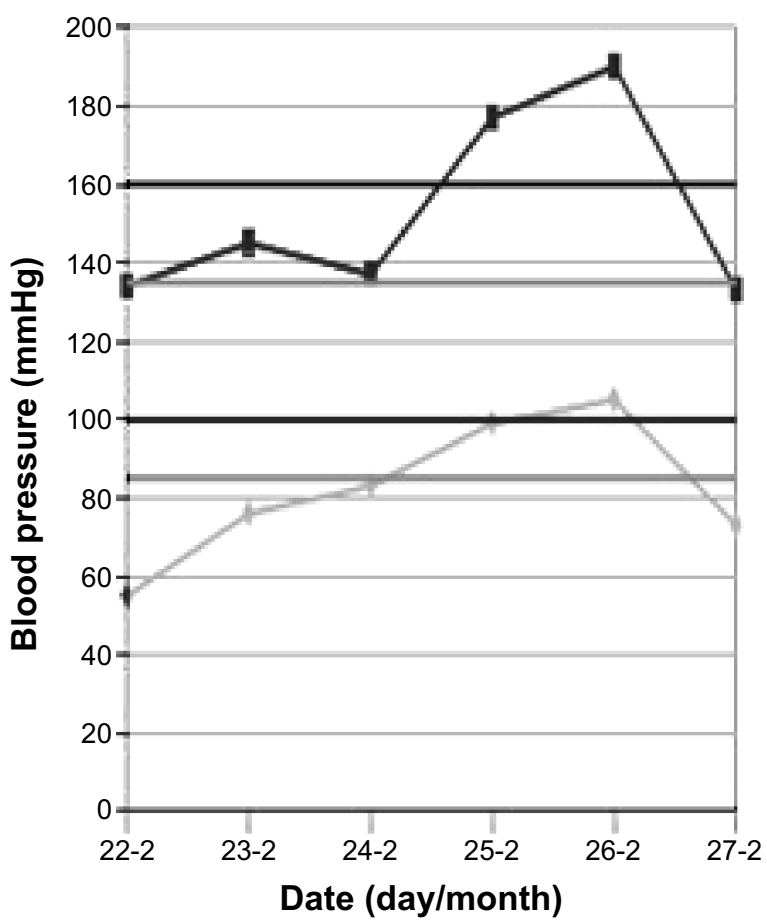

(B) Blood pressure measurements using reference lines as requested by participants.

Although feedback was appreciated by all participants with mild or severe hypertension, only one participant would intend to visit his/her general practitioner to discuss this. All participants indicated a willingness to wear their phone in a pocket for monitoring of physical activity. At the end of the usability test, participants were more experienced in using the smartphone application.

Results for perceived usability (as measured by the PSSUQ) are presented in Table 3. Participants perceived the smartphone application as useful (mean score $5.50 \pm 1.71$ on a scale of $1-7$, with a higher score indicating better usability) and of good information quality (mean score 5.96 \pm 63 ) and interface quality (mean score 5.68 \pm 1.83 ). Table 4 presents the results for the participants' motivation as measured by the TSRQ. Participants scored high on autonomous regulation (ie, intrinsic motivation) to use the smartphone application (mean score 5.44 \pm 2.42 ) and low on controlled regulation (ie, extrinsic motivation, mean score 1.32 \pm 0.67 ).

\section{Discussion}

This study explored whether offspring of dementia patients are motivated to participate in home-based health monitoring research by using iVitality. In addition, requirements for 
Table 2 Usability tasks concerning application of iVitality

\begin{tabular}{|c|c|c|c|c|c|}
\hline \multirow[t]{2}{*}{ Description of usability tasks } & \multirow[t]{2}{*}{$\begin{array}{l}\text { Results based on think aloud } \\
\text { and participant's performance }\end{array}$} & \multicolumn{4}{|c|}{$\begin{array}{l}\text { Participant's } \\
\text { reported experience } \\
\text { indicated by " } x \text { " }\end{array}$} \\
\hline & & $\mathbf{I}$ & 2 & 3 & 4 \\
\hline \multirow[t]{4}{*}{$\begin{array}{l}\text { I. Monitoring and registering blood } \\
\text { pressure data with the iVitality application. }\end{array}$} & $\begin{array}{l}\text { User had a problem in interpreting the menu } \\
\text { navigation structure of the application when } \\
\text { searching how to register the blood pressure results. }\end{array}$ & $x$ & $x$ & $x$ & $x$ \\
\hline & $\begin{array}{l}\text { The "back-tip" to undo a mistake did not work. } \\
\text { Bluetooth asked for authorization. The user was } \\
\text { confused and thought the data were visible to more } \\
\text { people. }\end{array}$ & $\begin{array}{l}x \\
x\end{array}$ & $x$ & $x$ & $x$ \\
\hline & $\begin{array}{l}\text { The application announced "busy gathering data" } \\
\text { instead of "start blood pressure measurement" } \\
\text { which confused the user. }\end{array}$ & $x$ & $x$ & $x$ & $x$ \\
\hline & $\begin{array}{l}\text { After the first measurement, the user thought he/she } \\
\text { could continue immediately with the second measurement. } \\
\text { Internet, or Wi-Fi connection was needed to see the } \\
\text { instruction video via the iVitality application. The user } \\
\text { did not know this. }\end{array}$ & & $x$ & & \\
\hline $\begin{array}{l}\text { 2. Comparing the new measured blood } \\
\text { pressure data with those measured before. }\end{array}$ & $\begin{array}{l}\text { Graphical presentation was not clear for users; users } \\
\text { could not read the former measured blood pressure } \\
\text { values from the smartphone display. }\end{array}$ & $x$ & $*$ & $x$ & $x$ \\
\hline \multirow[t]{2}{*}{ 3. Measuring physical activity. } & $\begin{array}{l}\text { Physical activity sensors are always active when } \\
\text { running the iVitality application. The user did not } \\
\text { know this and was not able to see this. }\end{array}$ & & $x$ & & \\
\hline & $\begin{array}{l}\text { Wearing the iVitality application daily for physical } \\
\text { activity was no problem. }\end{array}$ & $x$ & $x$ & $x$ & $x$ \\
\hline $\begin{array}{l}\text { 4. Version I: graphical presentation of measured } \\
\text { blood pressure data and a black reference line } \\
\text { of maximum permitted value according to participant's } \\
\text { age group. }\end{array}$ & $\begin{array}{l}\text { The user believed that the black line was the mean } \\
\text { blood pressure of the whole study group. The } \\
\text { representation of one's own value above this line was } \\
\text { not conceived as a problem. }\end{array}$ & $x$ & $x$ & $x$ & $x$ \\
\hline $\begin{array}{l}\text { 5. Version 2: graphical presentation of measured blood } \\
\text { pressure data and both gray and black reference lines } \\
\text { of "high" and "maximum" permitted values. }\end{array}$ & $\begin{array}{l}\text { The user did not understand the meaning of the gray } \\
\text { line. The user found two reference lines too much for } \\
\text { a good orientation. }\end{array}$ & $x$ & $x$ & $x$ & \\
\hline 6. Choosing only the one line or both references lines. & $\begin{array}{l}\text { See point } 5 . \text { The user preferred to maintain only one } \\
\text { reference line for early detection of having a "higher" } \\
\text { blood pressure. }\end{array}$ & & $x$ & & $x$ \\
\hline \multirow[t]{3}{*}{$\begin{array}{l}\text { 7. Feedback: which text do you prefer? And would you } \\
\text { undertake action? }\end{array}$} & $\begin{array}{l}\text { Feedback "light increase", "high", or "severe" blood } \\
\text { pressure is appreciated. }\end{array}$ & $x$ & $x$ & $x$ & $x$ \\
\hline & $\begin{array}{l}\text { Would undertake action when feedback provided } \\
\text { "high" or "severe" blood pressure. }\end{array}$ & & & & $x$ \\
\hline & $\begin{array}{l}\text { Would undertake no action when feedback was } \\
\text { "little increase". }\end{array}$ & $x$ & & $x$ & \\
\hline
\end{tabular}

Note: *No data available.

optimizing iVitality were formulated based on preferences of offspring of patients with dementia, and the technical functioning and usability of the smartphone-based application of iVitality were evaluated. Participants were motivated to contribute to dementia research by using iVitality, and, despite some technical shortcomings (which were adjusted accordingly in the new version of the application), the smartphone application was evaluated as easy to use, user-friendly, and useful. These findings are important, and suggest potential acceptance and usage of iVitality in the 6-month POP study that is currently being conducted in 150 persons who are offspring of patients with dementia.

Participants reported having autonomous (ie, intrinsic) motivation rather than controlled motivation regarding the use of the iVitality smartphone application. Higher autonomous motivation has been found to be associated with positive outcomes, as motivation evolves from one's personal values and is considered as part of the larger 
Table 3 Perceived ease of use and quality of the iVitality smartphone application for four participants (PSSUQ)

\begin{tabular}{llll}
\hline Domain & $\begin{array}{l}\text { Number of } \\
\text { questions }\end{array}$ & $\begin{array}{l}\text { Response rate } \\
\text { per domain (\%) }\end{array}$ & $\begin{array}{l}\text { Mean score } \\
\text { (SD) }\end{array}$ \\
\hline System ease of use and efficiency & 10 & 100 & $5.50(1.7 I)$ \\
Satisfied about ease of use and understanding how to use & 5 & 100 & 100 \\
Efficiency in doing tasks & 5 & $1.97)$ \\
Information quality & 6 & 100 & $5.75(1.4 I)$ \\
$\begin{array}{l}\text { Error handling, information easy to understand, } \\
\text { information helpful in doing tasks }\end{array}$ & & & \\
Interface quality & 8 & & \\
Letter quality, contrast, colors, easy to read, & & & $5.68(1.63)$ \\
easy to learn how it works & & & \\
\hline
\end{tabular}

Notes: Outcomes are measured on a 1-7 scale; higher scores refer to higher agreement.

Abbreviations: PSSUQ, Post-Study System Usability Questionnaire; SD, standard deviation.

self, while controlled motivation is often linked with less beneficial outcomes. ${ }^{16}$ Our findings demonstrate that participants positively endorse and value the iVitality, which may facilitate compliance with the subsequent POP study. Motivation is key to adherence with (home-based) research or self-monitoring protocols. ${ }^{19,20}$

Some participants indicated that they performed the measurements merely for research purposes, reporting that they did not expect to benefit or were not interested in the measurements themselves. Possibly, due to the so far unknown relationship between dementia and hypertension, participants have been mainly focused on stimulating research in this area. Clearly, addressing this relationship and its importance might stimulate self-monitoring and emphasize the importance and possible benefits of self-management of lifestyle factors. The use and acceptance of iVitality is, according to all participants, closely related to the frequency and timing of monitoring. The impact on participants' daily lives when collecting data during a certain time period should be taken into account when investigating and implementing such methods.

Usability evaluations revealed some shortcomings in need of attention, such as unclear notifications, menu navigations, or graphical representations, which were adjusted accordingly. In addition, due to the multiple consecutive iterations, participants' needs and preferences regarding the application or methods were processed in order to achieve an improved final version of the iVitality smartphone application. It remains conceivable, though, that problems or ambiguities in the application have been missed. A study by Faulkner states that more test users provide greater confidence in finding and fixing problems. ${ }^{21}$ Therefore, the benefits of having more test users should be weighed against the cost-saving but risky approach of a small set of test users.

The perceived importance of home-based self-monitoring, either with the purpose of contributing to dementia research or

Table 4 Motivation in using iVitality for four participants (TSRQ)

\begin{tabular}{|c|c|c|c|}
\hline Domain & $\begin{array}{l}\text { Mean per } \\
\text { question }\end{array}$ & $\begin{array}{l}\text { Response rate } \\
\text { per domain (\%) }\end{array}$ & $\begin{array}{l}\text { Mean score } \\
\text { (SD) }\end{array}$ \\
\hline Autonomous responses using iVitality & & 96 & $5.44(2.42)$ \\
\hline I. I feel it is a personal challenge & 1.3 & & \\
\hline 2. I made this choice on my own & 7.0 & & \\
\hline 3. I think I have benefit as a child of a demented elder & 5.5 & & \\
\hline 4. I find this important & 7.0 & & \\
\hline 5. I find this important for having insight into my condition & 5.0 & & \\
\hline 6. I like taking responsibility for my own care and/or lifestyle & 5.0 & & \\
\hline 7. I really believe it is the best thing for me to do & 7.0 & & \\
\hline Controlled responses using iVitality & & 95 & $1.32(0.67)$ \\
\hline I. I would feel bad about myself if I did not & 1.8 & & \\
\hline 2. I want others to approve of me & 1.3 & & \\
\hline 3. I want my partner and significant others to not be disappointed & 1.0 & & \\
\hline 4. I want my physician to see me as a "model" patient & 1.0 & & \\
\hline 5. I would feel guilty if I did not & 1.5 & & \\
\hline
\end{tabular}

Notes: Outcomes are measured on a I-7 scale; higher scores refer to higher agreement.

Abbreviations: TSRQ, Treatment Self-Regulation Questionnaire; SD, standard deviation. 
of gaining insight into one's own health, was acknowledged by participants. Remarkably, only one participant indicated having undertaken action when provided with feedback of having increased blood pressure. Previous research suggests that providing feedback on patients' health data is of importance and has the potential to empower patients, to influence their attitude and (health) behavior, and to improve their medical conditions. ${ }^{22-24}$ In addition, a clinical study on selfmonitoring by patients with chronic obstructive pulmonary disease showed that support by the care team can be established without requiring frequent visits and was effective in reducing hospital readmissions. ${ }^{25}$ In our case, a large-scale trial is warranted to examine whether users of iVitality would be successful in controlling and enhancing their health. This might require the incorporation of intervention elements into the iVitality platform that are focused on supporting users in changing their lifestyle and/or maintaining healthy behavior. It should be noted that when providing (graphical) feedback, the individual situation of the user should be taken into account in order to provide tailored advice. In the POP study, a study physician automatically receives a notification when a user's blood pressure values are outside the normal range and advises the user to contact their general practitioner.

Findings from the present study emphasize the potential interest of using home-based, novel technologies for health monitoring and self-management. Smartphone and Internet use is becoming more common, even among those aged 65 years or older. ${ }^{26,27}$ Using smartphone technology in medicine is becoming more popular and its impact on medicine has already been significant. The increasing uptake of innovative technologies enables remote monitoring of health-related indicators (eg, blood pressure), supports self-management of patients regarding lifestyle factors (eg, physical activity), and can improve accessibility and delivery of health care and interventions. ${ }^{22,28-30} \mathrm{It}$ is expected that this trend will continue in health care. Smartphones are already used to improve health, to collect data during medical trials, and to support clinical practice..$^{31,32}$ In addition, self-monitoring tools can involve relatively low installation and application costs. $^{25}$ In the event of (being at risk for) dementia, being able to record, analyze, and receive feedback on measured health values may not only potentially benefit offspring of patients with dementia by directly improving their lifestyle and thereby preventing, for example, hypertension, but also contributes to prevention research to untangle the relationship between risk factors and dementia.

The present study has some limitations. First, the number of participants was small. Therefore, our conclusions should be interpreted with caution, although there is no required minimum number of participants for conducting interviews, focus groups, or usability evaluations. The general size of a focus group varies between six and ten participants. ${ }^{17}$ For usability tests, five users are often enough to identify $80 \%$ of all usability problems. ${ }^{33-35}$ The optimal number of participants required for interviews is not clear. ${ }^{36}$ This depends on the details, thoughts and problems raised by participants, and whether the selected participants give an adequate reflection of existing demographic differences. However, despite the small number, participants with different profiles and backgrounds were included, and within this sample, theme saturation was achieved. Second, considering the fact that our participants were highly motivated to contribute to research regarding dementia, it might be the case that our sample is not representative for studies including the general population. All participants were recruited via the Dutch Alzheimer Foundation and might therefore share similar experiences and have a similar point of view toward using iVitality. Possibly, our study participants were more inclined to perform the measurements as required and to adopt the application as compared with less motivated users. Yet, our sample reflect the population of potential end-users of iVitality, thereby accentuating the importance of our results. By choosing a population that matches potential users, requirements may be more specific. Additionally, by using an iterative approach, aforementioned statements and comments by participants could be triangulated on validity in a subsequent phase. The forthcoming POP study, in which 150 offspring of patients with dementia will use iVitality for 6 months, may provide additional insights into users' expectations, acceptance, and experiences with iVitality.

\section{Conclusion}

Offspring of patients with dementia are motivated to contribute to home-based health monitoring by using iVitality. Important requirements that determined usefulness and ease of use in our study were the frequency and time interval of measurements, the (amount of) questions, and the visual features of iVitality. Usability evaluations are needed and can avoid deficits in research applications and research protocols. Participants in our study were able to use the smartphone application, and the reported user preferences, requirements, and evaluations will be embedded to optimize iVitality.

\section{Acknowledgments}

The authors thank all those who participated in this study. A first prototype of the online iVitality research platform has 
been developed within the framework of the Netherlands Consortium for Healthy Aging and the Leiden University Medical Centre. iVitality is part of the PROBE (PReservation Of Brain function in the Elderly) study. This work was supported by the Dutch Ministry of Health, Welfare and Sport and was enabled by ZonMw (NGI/NWO 050-060-810 project 627002001).

\section{Disclosure}

The authors report no conflicts of interest in this work.

\section{References}

1. Barnes DE, Yaffe K. The projected effect of risk factor reduction on Alzheimer's disease prevalence. Lancet Neurol. 2011;10(9):819-828.

2. Thies W, Bleiler L. 2013 Alzheimer's disease facts and figures. Alzheimers Dement. 2013;9(2):208-245.

3. Prince M, Bryce R, Albanese E, Wimo A, Ribeiro W, Ferri CP. The global prevalence of dementia: a systematic review and metaanalysis. Alzheimers Dement. 2013;9(1):63-75.e62.

4. Launer LJ, Hughes T, Yu B, et al. Lowering midlife levels of systolic blood pressure as a public health strategy to reduce late-life dementia perspective from the Honolulu heart program/Honolulu Asia Aging Study. Hypertension. 2010;55(6):1352-1359.

5. Angevaren M, Aufdemkampe G, Verhaar H, Aleman A, Vanhees L. Physical activity and enhanced fitness to improve cognitive function in older people without known cognitive impairment. Cochrane Database Syst Rev. 2008;3:CD005381.

6. Peters R, Beckett N, Forette F, et al. Incident dementia and blood pressure lowering in the Hypertension in the Very Elderly Trial cognitive function assessment (HYVET-COG): a double-blind, placebo controlled trial. Lancet Neurol. 2008;7(8):683-689.

7. van Exel E, Eikelenboom P, Comijs H, et al. Vascular factors and markers of inflammation in offspring with a parental history of late-onset Alzheimer disease. Arch Gen Psychiatry. 2009;66(11):1263-1270.

8. Green RC, Cupples LA, Go R, et al. Risk of dementia among white and African American relatives of patients with Alzheimer disease. JAMA. 2002;287(3):329-336.

9. Neerincx MA, Lindenberg J. Situated cognitive engineering for complex task environments. In: Schraagen JMC, Militello L, Ormerod T, Lipshitz R, editors. Naturalistic Decision Making and Macrocognition. Aldershot, UK: Ashgate Publishing Limited; 2008.

10. Farrer LA, Cupples LA, van Duijn CM, Connor-Lacke L, Kiely DK, Growdon JH. Rate of progression of Alzheimer's disease is associated with genetic risk. Arch Neurol. 1995;52(9):918.

11. Giacomini MK, Cook DJ. Users' guides to the medical literature: XXIII. Qualitative research in health care A. Are the results of the study valid? Evidence-Based Medicine Working Group. JAMA. 2000;284(3):357-362.

12. Visser FS, Stappers PJ, Van der Lugt R, Sanders EB. Context mapping: experiences from practice. Co Design. 2005;1(2):119-149.

13. Sanders EB-N, William CT. Harnessing people's creativity: ideation and expression through visual communication. In: Langford J, McDonaghPhilp D, editors. Focus Groups: Supporting Effective Product Development. London, UK: Taylor and Francis; 2003.

14. Venkatesh V, Davis FD. A theoretical extension of the technology acceptance model: four longitudinal field studies. Manag Sci. 2000;46(2): 186-204.

15. Lewis JR. Psychometric evaluation of the post-study system usability questionnaire: The PSSUQ. Paper presented at the Human Factors and Ergonomics Society 36th Annual Meeting, Atlanta, GA, October 12-16, 1992.

16. Levesque CS, Williams GC, Elliot D, Pickering MA, Bodenhamer B, Finley PJ. Validating the theoretical structure of the Treatment SelfRegulation Questionnaire (TSRQ) across three different health behaviors. Health Educ Res. 2007;22(5):691-702.
17. King N. Template analysis. In: Cassell C, Symon G, editors. Qualitative Methods and Analysis in Organizational Research: A Practical Guide. London, UK; Thousand Oaks, CA, USA.: Sage Publications; 1998.

18. MAXQDA. VERBI software for qualitative data analysis. BerlinMarburg-Amöneburg, Germany: Consult. Sozialforschung GmbH. 1989-2010. Available from: http://www.maxqda.com/. Accessed April 26, 2015.

19. Gaikwad R, Warren J. The role of home-based information and communications technology interventions in chronic disease management: a systematic literature review. Health Informatics J. 2009;15(2): $122-146$.

20. Marshall A, Medvedev O, Antonov A. Use of a smartphone for improved self-management of pulmonary rehabilitation. Int $J$ Telemed Appl. 2008;2008:753064.

21. Faulkner L. Beyond the five-user assumption: benefits of increased sample sizes in usability testing. Behav Res Methods Instrum Comput. 2003;35(3):379-383.

22. Bodenheimer T, Lorig K, Holman H, Grumbach K. Patient selfmanagement of chronic disease in primary care. JAMA. 2002;288(19): 2469-2475.

23. Paré G, Jaana M, Sicotte C. Systematic review of home telemonitoring for chronic diseases: the evidence base. J Am Med Informatics Assoc. 2007;14(3):269-277.

24. Rao A, Hou P, Golnik T, Flaherty J, Vu S. Evolution of data management tools for managing self-monitoring of blood glucose results: a survey of iPhone applications. J Diabetes Sci Technol. 2010;4(4):949-957.

25. de Toledo P, Jiménez S, del Pozo F, Roca J, Alonso A, Hernandez C. Telemedicine experience for chronic care in COPD. IEEE Trans Inf Technol Biomed. 2006;10(3):567-573.

26. CBS. ICT, knowledge and the economy 2013. CBS, The Hague/Heerlen, The Netherlands. Available from: http://www.cbs.nl/en-GB/menu/ themas/bedrijven/publicaties/digitale-economie/publicaties/2013ict-kennis-economie-2012-pub.htm?Languageswitch $=$ on. Accessed November 13, 2013.

27. Zickuhr K, Madden M. Older adults and Internet use. Pew Internet and American Life Project, 2012. Available from: http://www.pewinternet. org/2012/06/06/older-adults-and-internet-use/. Accessed April 26, 2015.

28. Asmar R, Zanchetti A. Guidelines for the use of self-blood pressure monitoring: a summary report of the first international consensus conference. J Hypertens. 2000;18(5):493-508.

29. Margolis KL, Asche SE, Bergdall AR, et al. Effect of home blood pressure telemonitoring and pharmacist management on blood pressure control: a cluster randomized clinical trial. JAMA. 2013;310(1):46-56.

30. O’Brien E, Waeber B, Parati G, Staessen J, Myers MG. Blood pressure measuring devices: recommendations of the European Society of Hypertension. BMJ. 2001;322(7285):531-536.

31. Boulos MN, Wheeler S, Tavares C, Jones R. How smartphones are changing the face of mobile and participatory healthcare: an overview, with example from eCAALYX. Biomed Eng Online. 2011; 10(1):24.

32. Ozdalga E, Ozdalga A, Ahuja N. The smartphone in medicine: a review of current and potential use among physicians and students. $J$ Med Internet Res. 2012;14(5):e128.

33. Nielsen J, Landauer TK. A mathematical model of the finding of usability problems. Paper presented at the INTERACT'93 and CHI'93 Conference on Human Factors in Computing Systems, April 24-29, 1993, Amsterdam, The Netherlands.

34. Nielsen J. Why you only need to test with 5 users. Alertbox, 2000. Available from: http://www.nngroup.com/articles/why-you-only-needto-test-with-5-users/. Accessed April 26, 2015.

35. Turner CW, Lewis JR, Nielsen J. Determining usability test sample size. In: Karwowski W, editor. International Encyclopedia of Ergonomics and Human Factors. Oxford, UK: CRC Press; 2006.

36. Beatty PC, Willis GB. Research synthesis: the practice of cognitive interviewing. Public Opin Q. 2007;71(2):287-311. 
Patient Preference and Adherence

Dovepress

\section{Publish your work in this journal}

Patient Preference and Adherence is an international, peer-reviewed, open access journal that focuses on the growing importance of patient preference and adherence throughout the therapeutic continuum. Patient satisfaction, acceptability, quality of life, compliance, persistence and their role in developing new therapeutic modalities and compounds to optimize

Submit your manuscript here: http://www.dovepress.com/patient-preference-and-adherence-journa clinical outcomes for existing disease states are major areas of interest for the journal. This journal has been accepted for indexing on PubMed Central The manuscript management system is completely online and includes a very quick and fair peer-review system, which is all easy to use. Visit http://www. dovepress.com/testimonials.php to read real quotes from published authors. 